\title{
In vivo antimalarial activity of the crude leaf extract of Combretum molle against Plasmodium berghei in mice
}

\section{CURRENT STATUS: POSTED}

Research Square

Melkamu Adigo Shibeshi

Awi health department

Tezera Jemere Aragaw

University of Gondar

tezeraadis1982@gmail.comCorresponding Author

Getnet Mequanint Adinew

University of Gondar

Engdaw Fentahun Enyew

University of Gondar

DOI:

$10.21203 / \mathrm{rs} .2 .22912 / \mathrm{v} 1$

SUBJECT AREAS

Infectious Diseases

KEYWORDS

Antimalarial, Combretum molle, crude extract, Plasmodium berghei, sub-acute toxicity 
Abstract

Background Malaria is an infectious, hematologic disease causing death and illness in children and adults, especially in tropical countries. The aim of this study was to evaluate the antimalarial activity of Combretum molle extract in vivo assays against Plasmodium berghei in Swiss albino mice.

Methods Plasmodium berghei a rodent malaria parasite was inoculated to healthy Swiss Albino mice age 6-8 weeks either sex, weight 20-33g. 100, 200 and 400mg/kg/day of Crude methanolic extract of Combretum molle were administered. Parameters such as Percent parasitemia, body weight, Body temperature, packed cell volume and survival time were then determined using standard tests. Data were analyzed using one-way ANOVA followed by the Post hoc Tukey HSD test with SPSS software version 24.0 and $P \leq 0.05$ considered as statistically significant.

Results Chemosuppresive effect exerted by the crude extract ranged between $27-68 \%$. The curative effect of the crude extract was in the range of $25-49 \%$ and ptophylactic effect of the crude extract was in the range of $51-76.2 \% \%$. The maximum effect in all tests on Chemosuppresive, curative, Prophylactic, prevention of weight loss, body temperature and packed cell volume and an increase in mean survival time was observed at higher doses of the crude extract.

Conclusion From the present study it can be concluded that the crude extract of Combretum molle leaves has been shown promising antimalarial activity. This finding supports the traditional use of the plant for the treatment of malaria in Ethiopia. Thus, it could be considered as a potential source to develop safe, effective and affordable antimalarial agent.

Full-text

Due to technical limitations, full-text HTML conversion of this manuscript could not be completed. However, the manuscript can be downloaded and accessed as a PDF.

\section{Supplementary Files}

This is a list of supplementary files associated with this preprint. Click to download.

Crude data of Methanolic extract of C. molle leaf.xIsx

Drugs, Chemicals and materials.docx 